\title{
Preparation and Cu (II) Adsorption Characteristics of Carboxymethyl Cross-Linked Sewage Sludge
}

\author{
Ting Wang, Weican Zhang*, Xuemei Lu \\ State Key Laboratory of Microbial Technology, Shandong University, Jinan, \\ Shandong, 250100, China
}

Received: 3 April 2015

Accepted: 4 December 2015

\begin{abstract}
Sewage sludge was cross-linked with epichlorohydrin to increase its mechanical strength and applicability as an absorbent material. We investigated the effect of the conditions of the cross-linking reaction on the mechanical strength and $\mathrm{Cu}$ (II) adsorption capacity of epichlorohydrin cross-linking sewage sludge (ECS). Experimental results showed that cross-linking can raise significantly the mechanical strength of sewage sludge. To improve the adsorption capacity of ECS, carboxymethyl cross-linked sewage sludge (CCS) with maximal adsorption capacity (65mg/g) for $\mathrm{Cu}$ (II) was synthesized from ECS by using chloroacetic acid as the etherification agent. The experimental results showed that the adsorption properties of CCS for Cu (II) could best be described by the pseudo-second order model and Langmuir model, and the adsorption mechanism was ion exchange. Our data suggest that CCS is a promising absorbent for removal of heavy metals from wastewater.
\end{abstract}

Keywords: sewage sludge, cross-linked sewage sludge, carboxymethyl cross-linked sewage sludge, heavy metal adsorption

\section{Introduction}

Sewage sludge is residue generated at centralized wastewater treatment plants as a result of the treatment of wastes released from a variety of sources, including homes, industries, medical facilities, street runoff, and businesses. In the past decades, sewage sludge has dramatically increased due to rapid urbanization and has resulted in serious environmental problems. Thus, disposal and resource use of sewage sludge have attracted

*e-mail: weican@sdu.edu.cn much attention [1-4]. Traditional methods for disposing of sewage sludge include application to cropland, landfilling, incineration, and ocean dumping, which have been operated in some countries for many years $[5,6]$. The negative environmental effects of these methods have gradually been reflected by the transfer of pollutants from sewage sludge to the soil, the atmosphere, and the ocean. The demand for efficient and environmentally friendly approaches to the utilization of sewage sludge is therefore a matter of urgency. One of these is conversion of sewage sludge into adsorbents.

Many different methods have been proposed and used to convert this waste to a variety of sewage sludgebased adsorbents [6-14], including pyrolysis, chemical 
activation, microwave irradiation, and alkali modification, etc. Because sewage sludge contains carbon and can be made into cheap adsorbents, much research has focused on making use of sewage sludge to prepare carbon-bearing adsorbents for the removal of pollutants from wastewater [10-14]. In fact, sewage sludge is a solid-liquid mixture containing organic fragments, bacteria, inorganic particles, and colloids [15], and has good adsorption performance.

Living bio-sludge acclimatized in synthetic industrial estate wastewater without heavy metals showed the highest $\mathrm{Pb}$ (II) and $\mathrm{Ni}$ (II) adsorption capacities at 840 and $720 \mathrm{mg} / \mathrm{g}$ biosludge, respectively [16]. However, it is difficult for sewage sludge as an adsorbent to be directly used for industrial sites since it tends to break up and disperse in aqueous solutions. Therefore, sewage sludgebased adsorbents with high mechanical strength and adsorption efficiency should be developed, but the related work has not been reported.

The pollution of water resources due to the indiscriminate disposal of heavy metals has been causing worldwide concern for the last few decades. Copper is one of the most important and frequently used metals in industries such plating, mining, and petroleum refining [8]. These industries produce a great amount of wastewater and sludge containing a high concentration of copper cations, which have negative effects on the water environment. Hence, the removal and recovery of copper from contaminated water and wastewater is important in the protection of the environment and human health.

In this work, sewage sludge was cross-linked with epichlorohydrin to increase its mechanical strength. The effect of the conditions of the cross-linking reaction on the mechanical strength of epichlorohydrin cross-linking sewage sludge (ECS) was investigated. Based on this, carboxymethyl cross-linked sewage sludge (CCS) with high mechanical strength was synthesized from ECS by using chloroacetic acid as the etherification agent. Meanwhile, the adsorption properties of ECS and CCS for $\mathrm{Cu}$ (II) were studied. Our data suggest that highmechanical-strength CCS is a promising absorbent for removing heavy metals from wastewater.

\section{Materials and Methods}

\section{Materials}

The solid excess sewage sludge (water content: $70 \%$ $(\mathrm{w} / \mathrm{w})$ ) used in this work came from the Everbright Wastewater Treatment Plant in Jinan, Shandong Province, China. All the reagents used were purchased from Sinopharm Chemical Reagent Co. Ltd.

\section{Preparation of Sewage Sludge Rods}

Solid sewage sludge strips about $1 \mathrm{~mm}$ in diameter were prepared by the extrusion molding method with syringes, and then the strips were cut into rods about $5 \mathrm{~mm}$ long. The resulting sewage sludge rods were dried for $12 \mathrm{~h}$ at $60^{\circ} \mathrm{C}$, and then stored in a dryer for later use.

\section{Preparation of Epichlorohydrin Cross-linked Sewage Sludge Rods (ECS)}

Five grams of solid sewage sludge rods and an appropriate amount of $\mathrm{NaOH}$ were suspended in $50 \mathrm{~mL}$ of ethanol with stirring for two hours at room temperature. Then different amounts of epichlorohydrin were added and the the mixture was allowed to react for $8 \mathrm{~h}$ at different temperatures. The product was subsequently neutralized by washing with an excess of distilled water. Finally, the sample was dried for $12 \mathrm{~h}$ at $60^{\circ} \mathrm{C}$ and stored in a dryer for the determination of its adsorption and mechanical properties.

\section{Preparation of Carboxymethyl Cross-linked Sewage Sludge Rods (CCS)}

Carboxymethyl cross-linked sewage sludge was prepared by a modified Kim and Lim's method [17]. $5 \mathrm{~g}$ of ECS and $5 \mathrm{~g}$ of $\mathrm{NaOH}$ were suspended in $50 \mathrm{ml}$ of ethanol with stirring for two hours at room temperature. $5 \mathrm{~g}$ of chloroacetic acid was added and the mixture was allowed to react for $6 \mathrm{~h}$ at $80^{\circ} \mathrm{C}$. After the reaction, the product was subsequently neutralized by washing with an excess of distilled water, and then dried for $12 \mathrm{~h}$ at $60^{\circ} \mathrm{C}$. Finally the sample was stored in a dryer for the determination of its adsorption and mechanical properties.

\section{Adsorption Experiments of ECS and CCS}

An aqueous solution of copper ions was prepared by dissolving cupric sulfate $\left(\mathrm{CuSO}_{4} \cdot 5 \mathrm{H}_{2} \mathrm{O}\right)$ in distilled water. ECS or CCS (about $0.2 \mathrm{~g}$ ) was added to $100 \mathrm{mg} / \mathrm{L}$ of $\mathrm{Cu}$ (II) copper sulfate solution (200 ml, pH 5), and the mixture was shaken on a rotating shaker for $72 \mathrm{~h}$ at $150 \mathrm{rpm}$ at $30^{\circ} \mathrm{C}$. The concentration of $\mathrm{Cu}$ (II) remaining in the supernatant was determined by means of spectrophotometry using the $\mathrm{Cu}$ (II) dicyclohexanoneoxaly dihydrazone colour system (Shimadzu UV-3100 spectrophotometer with $600 \mathrm{~nm}$ ) [18]. The amount of Cu (II) adsorbed on ECS or CCS, Qe (mg/g dry weight), was calculated from the mass balance equation:

$$
Q e=\left(C_{0}-C_{e}\right) V / m
$$

...where $C_{0}$ and $C_{e}$ are the concentrations of $\mathrm{Cu}$ (II) at initial and measuring time in the solution, $V$ is the volume of the aqueous solution, and $m(\mathrm{~g})$ is the weight of the CSS or CCS.

\section{Evaluation of Mechanical Strength of ECS and CCS}

Referencing the measuring method of friability of powder material [19], the mechanical strength of ECS and CCS was evaluated by their loss-weight rate (LWR) in the 
shaking process. ECS or CCS (about $1.0 \mathrm{~g}, W_{1}$ ) was added to $100 \mathrm{ml}$ of distilled water in a $250 \mathrm{ml}$ reagent bottle and the mixture was shaken on a rotating shaker for $72 \mathrm{~h}$ at $200 \mathrm{rpm}$ at $30^{\circ} \mathrm{C}$. Then the samples above 20 mesh (pore diameter $800 \mathrm{um}$ ) were collected, dried for $12 \mathrm{~h}$ at $60^{\circ} \mathrm{C}$, and weighed $\left(\mathrm{W}_{2}\right)$ again. $L W R$ was calculated from the equation:

$$
\begin{gathered}
L W R=\left(W_{1}-W_{2}\right) / W_{1} \times 100 \% \\
\text { Effect of pH on Adsorption of Cu (II) } \\
\text { on CCS }
\end{gathered}
$$

The effect of $\mathrm{pH}$ on the adsorption amount of $\mathrm{Cu}$ (II) on CCS was studied at $\mathrm{pH}$ values ranging from two to five (adjusted with $\mathrm{HCl}$ ) using a process similar to the alreadydescribed adsorption experiments.

\section{Infrared Spectroscopy}

Infrared spectra were recorded in $\mathrm{KBr}$ discs on a Nicolet AVATAR370 FTIR spectrometer under dry air at room temperature. An appropriate amount of the dried sewage sludge or ECS or CCS was blended with $\mathrm{KBr}$ (IR grade) and some of the mixture was pelleted for IR spectral measurement.

\section{Results and Discussion}

\section{Effect of Amount of Added Epichlorohydrin on Qe and LWR of ECS}

In the procedure of synthesis of ECS (method: preparation of epichlorohydrin cross-linking sewage sludge rods), the amount of added $\mathrm{NaOH}$ was $5 \mathrm{~g}$, and the temperature for reaction was $60^{\circ} \mathrm{C}$. The influence of the amount of added epichlorohydrin on Qe and LWR of ECS is shown in Table 1. It can be seen that the LWR of ECS rapidly decreases with increasing amounts of added epichlorohydrin over the range $0-25 \mathrm{ml}$, suggesting that the mechanical property is improved in this process. However, change of the mechanical strength was not obvious when the amount of epichlorohydrin was above $25 \mathrm{ml}$. It can also be seen from Table 1 that the adsorption ability of ECS changes very little when increasing the amount of added epichlorohydrin over the range 10-30 $\mathrm{ml}$. This result indicates that the cross-linking reaction of epichlorohydrin with sewage sludge has little influence on

Table 1. Effect of amount of added epichlorohydrin on Qe and LWR of ECS.

\begin{tabular}{|c|c|c|c|c|c|}
\hline No. & 1 & 2 & 3 & 4 & 5 \\
\hline Epichlorohyrin(ml) & 0 & 10 & 20 & 25 & 30 \\
\hline Qe (mg /g) & 51 & 34 & 34 & 35 & 36 \\
\hline LWR & 98 & 42 & 15 & 7.8 & 7.3 \\
\hline
\end{tabular}

Table 2. Effect of amount of added $\mathrm{NaOH}$ on Qe and LWR of ECS.

\begin{tabular}{|c|c|c|c|c|c|}
\hline No. & 1 & 2 & 3 & 4 & 5 \\
\hline NaOH (g) & 0 & 2 & 4 & 6 & 8 \\
\hline Qe (mg/g) & 27 & 32 & 35 & 35 & 36 \\
\hline LWR & 67 & 45 & 19 & 7.5 & 8.0 \\
\hline
\end{tabular}

the density of the adsorption sites of $\mathrm{Cu}$ (II) on sewage sludge. It is noteworthy that the amount of $\mathrm{Cu}$ (II) adsorption on the ECS (No. 1 in Table 1) (51mg/g) was obviously more than other samples when the amount of added epichlorohydrin was zero. There are two possible reasons for this phenomenon. First, the $\mathrm{NaOH}$-treated sewage sludge easily disperses during the adsorption experiments because of the lack of the cross-linked structure of epichlorohydrin and possessing high surface areas. Second, $\mathrm{NaOH}$ reacts with some sewage sludge constitutions, such as amides and esters, to form new functional groups with the adsorption ability for $\mathrm{Cu}$ (II).

As the above results showed, ECS possesses better mechanical properties and adsorption ability when the amount of added epichlorohydrin is $25 \mathrm{ml}$. Based on this, the effect of $\mathrm{NaOH}$ on Qe and the mechanical property of ECS were further investigated.

\section{Effect of Amount of Added $\mathrm{NaOH}$ on Qe and LWR of ECS}

Table 2 shows the effect of the amount of added $\mathrm{NaOH}$ on Qe and LWR of ECS. The preparation conditions of these samples were the same as those of the above section except that the amount of added epichlorohydrin was $25 \mathrm{ml}$. It can be seen from Table 2 that ECS has good mechanical properties when the amount of $\mathrm{NaOH}$ is more than $4 \mathrm{~g}$. The results of Table 2 also show that Qe has a slowly increasing tendency with an increasing amount of $\mathrm{NaOH}$. The probable reason for this, revealed by the above section, is that $\mathrm{NaOH}$ reacts with some sewage sludge constitutions to form some new functional groups with the adsorption ability for $\mathrm{Cu}$ (II).

\section{Effect of Temperature on Qe and LWR of ECS}

At the optimal amount of added $\mathrm{NaOH}(5 \mathrm{~g})$ and epichlorohydrin $(25 \mathrm{ml})$, the influence of the temperature on Qe and LWR of ECS is shown in Table 3. The results show that ECS has good mechanical properties when the

Table 3. Effect of temperature on Qe and LWR of ECS.

\begin{tabular}{|c|c|c|c|c|}
\hline No. & 1 & 2 & 3 & 4 \\
\hline Temperature $\left({ }^{\circ} \mathrm{C}\right)$ & 20 & 40 & 60 & 80 \\
\hline Qe (mg/g) & 38 & 39 & 35 & 35 \\
\hline LWR & 56 & 43 & 7.5 & 9.0 \\
\hline
\end{tabular}


reaction temperature is higher than $60^{\circ} \mathrm{C}$. However, the effect of the temperature in the range of $20-80^{\circ} \mathrm{C}$ on Qe was insignificant.

According to the above experimental results, the optimum synthetic conditions for ECS with good adsorption ability and mechanical properties are as follows: the reaction temperature is $60^{\circ} \mathrm{C}$ and the amount of the added epichlorohydrin and $\mathrm{NaOH}$ are $25 \mathrm{ml}$ and $5 \mathrm{~g}$, respectively. The resulting sample (ECS No. 3 in Table 3) was named ECSi.

\section{Kinetics of Carboxymethyl Cross-linked Sewage Sludge}

Usually, metal binding to sewage sludge occurs via ion exchange as well as by electrostatic interaction, and the major binding sites are the carboxyl groups [20]. To improve the adsorption capacity of ECSi, carboxymethyl cross-linked sewage sludge (CCS) was synthesized from it. The adsorbed amounts of $\mathrm{Cu}$ (II) on the CCS as a function of time at $100 \mathrm{mg} \mathrm{Cu}$ (II) / L (200 ml, $\mathrm{pH}$ 5) initial concentration are presented in Fig. 1 (a). In addition, the LWR of CCS is 8.7, indicating that it possesses good mechanical properties. To illustrate the validity of carboxymethylation, adsorption kinetics of ECSi for Cu (II) are shown in Fig. 1 (b). It can be seen that the maximum adsorption amount of CCS for $\mathrm{Cu}$ (II) is $55 \mathrm{mg} / \mathrm{g}$, noticeably more than that of ECSi (35 mg/g).

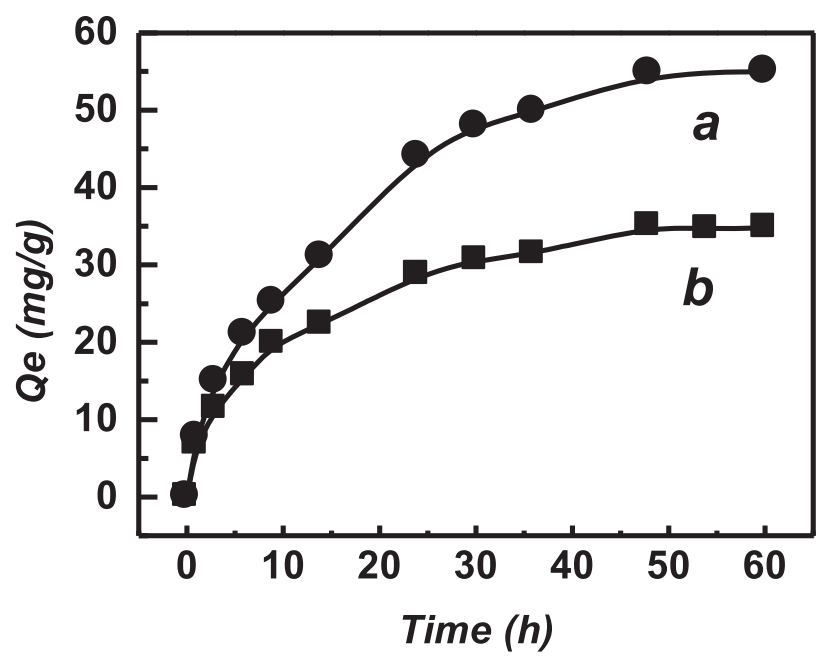

Fig. 1. Adsorbed amounts of Cu (II) on CCS (a) and ECSi (b) as a function of time at $100 \mathrm{mg} \mathrm{Cu}$ (II) /L initial concentration (200 $\mathrm{ml}, \mathrm{pH}$ ) at $30^{\circ} \mathrm{C}$.
However, the adsorption equilibrium of CCS and ECSi are the same amount of time, roughly $50 \mathrm{~h}$.

Several kinetic models are often applied to fit experimental data and to study the mechanisms of the adsorption process. Among them, the pseudo first-order equation, the pseudo second-order equation, and the Weber-Morris method are the most commonly used to describe adsorption kinetics of an adsorbate onto an adsorbent. When the adsorption process is determined by diffusion steps, the kinetics follows the pseudo-first-order rate equation of Lagergren [21-23],

$$
\frac{d Q_{t}}{d t}=k_{1}\left(Q_{e}-Q_{t}\right)
$$

... where $k_{1}$ is the first-order rate constant, $Q_{e}$ the amount of adsorbate adsorbed at equilibrium, and $Q_{t}$ the amount of adsorbate adsorbed at time $t$. The above equation can be transformed into the following formulation utilizing the integration:

$$
\log \left(Q_{e}-Q_{t}\right)=\log Q_{e}-\left(\frac{k_{1}}{2.303}\right) t
$$

The plot of $\log \left(Q_{e}-Q_{t}\right) v s$. $t$ gives a straight line, which allows computation of the adsorption rate constant, $k_{1}$.

The pseudo-second-order equation is given in the following form:

$$
\frac{d Q_{t}}{d t}=k_{2}\left(Q_{e}-Q_{t}\right)^{2}
$$

...where $k_{2}$ is the second-order rate constant, and the others are the same as in equation 1 .

This model is more likely to predict the kinetic behavior of adsorption with chemical adsorption being the rate-controlling step [22]. Integrating this equation for boundary conditions $t=0\left(Q_{t}=0\right)$ to $t\left(Q_{t}=Q_{e}\right)$ and then linearizing leads to

$$
\frac{t}{Q_{t}}=\frac{1}{k_{2} Q_{e}^{2}}+\frac{1}{Q_{e}} t
$$

The second-order rate constants $k_{2}$ and $Q_{e}$ are determined from the slope and intercepts of the plot obtained by plotting $t / Q_{t}$ versus $t$.

Table 4. Kinetic Parameters for adsorption of $\mathrm{Cu}(\mathrm{II})\left(C_{0}=100 \mathrm{mg} / \mathrm{L}\right)$ onto the CCS and ECSi.

\begin{tabular}{|c|c|c|c|c|c|c|c|}
\hline \multirow{2}{*}{} & \multicolumn{2}{|c|}{ Pseudo first order } & \multicolumn{2}{c|}{ Pseudo second order } & \multicolumn{3}{c|}{ Weber-Morris } \\
\cline { 2 - 9 } & $\mathrm{k}_{1}\left(\mathrm{~h}^{-1}\right)$ & $\mathrm{R}^{2}$ & $\mathrm{k}_{2}(\mathrm{~g} /(\mathrm{mg} \cdot \mathrm{h}))$ & $\mathrm{R}^{2}$ & $\mathrm{~K}_{\mathrm{d}}\left(\mathrm{mg} /\left(\mathrm{g} . \mathrm{h}^{1 / 2}\right)\right)$ & $\mathrm{C}(\mathrm{mg} / \mathrm{g})$ & $\mathrm{R}^{2}$ \\
\hline ECSi & 0.080 & 0.97 & 0.0039 & 0.99 & 4.5 & 3.6 & 0.96 \\
\hline CCS & 0.095 & 0.88 & 0.0018 & 0.99 & 7.71 & 1.81 & 0.98 \\
\hline
\end{tabular}


An intraparticle diffusion model proposed by Weber and Morris is as follows [22]:

$$
Q_{t}=K_{d} t^{1 / 2}+C
$$

...where $K_{d}$ is the rate constant of intraparticle diffusion and $C$ is the value of the intercept, which gives an idea about the boundary layer thickness, i.e., the larger the intercept, the greater the boundary layer effect.

The parameters of the linear fitting on $t / Q_{t} v s . t, \log$ $\left(Q_{e}-Q_{t}\right)$ vs. $t$ and $Q_{t} v s . t^{1 / 2}$ for data of Fig. 1 are given in Table 4. As shown in Table 4, the adsorption of $\mathrm{Cu}$ (II) on CCS and ECSi is best described by the pseudo secondorder model, indicating that chemical adsorption is the rate-controlling step in the kinetic process.

\section{Adsorption Isotherm of Cu (II) on CCS}

The adsorption isotherm $\mathrm{Cu}$ (II) on CCS is plotted in Fig. 2 (a). This isotherm describes the equilibrium between the adsorbed $\mathrm{Cu}$ (II) concentration (Qe) in milligrams per gram of CCS (mg/g) and the concentration of $\mathrm{Cu}$ (II) remaining in solution (Ce) in $\mathrm{mg} / \mathrm{L}$. It is clear that the amount of $\mathrm{Cu}$ (II) adsorbed on the CCS linearly increases to $40 \mathrm{mg} / \mathrm{g}$ with an increase of the equilibrium concentration of $\mathrm{Cu}$ (II) (Ce) to $10 \mathrm{mg} / \mathrm{L}$. When Ce is above $45 \mathrm{mg} / \mathrm{L}$, the increase of Qe becomes slower. As shown in Fig. 2 (a), the maximal adsorption capacity of CCS for $\mathrm{Cu}$ (II) is $65 \mathrm{mg} / \mathrm{g}$. As a comparison, the adsorption isotherm of $\mathrm{Cu}$ (II) on ECSi is presented in Fig. 2 (b). The maximal adsorption capacity of the CCS is much larger than that of ECSi (44 mg/g), indicating that carboxymethylation is an effective way to increase the adsorption ability of ECS.

In order to elucidate the adsorption mechanism of the CCS and ECSi for Cu (II), two important isotherms were selected in this study: the Langmuir and the Freundlich isotherm models [21-23]. The Langmuir model is obtained under the ideal assumption of a totally homogeneous adsorption surface and the adsorbate on the adsorbent with the monomolecular layer, whereas the Freundlich isotherm is suitable for a highly heterogeneous surface. The Langmuir model can be expressed by:

$$
Q_{e}=\frac{k_{L} Q_{\max } C_{e}}{1+k_{L} C_{e}}
$$

... where $Q_{e}$ is the amount of $\mathrm{Cu}$ (II) adsorbed (mg/g), $C_{e}$ is the equilibrium concentration of $\mathrm{Cu}(\mathrm{II})(\mathrm{mg} / \mathrm{L})$, and $k_{L}$ and $Q_{\max }$ are Langmuir constants.

The parameters $k_{L}$ and $Q_{\max }$ are computed from the linear form of Eq. (6):

$$
\frac{C_{e}}{Q_{e}}=\frac{C_{e}}{Q_{\max }}+\frac{1}{k_{L} Q_{\max }}
$$

For the Freundlich model, the amount of adsorbate adsorbed, $Q_{e}$, is related to the concentration of adsorbate in the solution $C_{e}$ through the following equation:

$$
Q_{e}=k_{f} C_{e}^{1 / n}
$$

...where $K_{f}$ and n are the Freundlich constants. They can be gained from the linear form of Eq. (9):

$$
\log Q_{e}=\frac{1}{n} \log C_{e}+\log k_{f}
$$

Experimental data in Fig. 2 were fitted to Eq. (7) and Eq. (9). The values of Langmuir constants $k_{L}$ and $Q_{\max }$ and Freundlich parameters $K_{f}$ and $n$ are presented in Table 5. The data are better fitted to the Langmuir model than to the Freundlich model. It is inferred that the adsorption surface of CCS and ECSi is closely homogenous. The above results demonstrate that the adsorption characteristics of both CCS and ECSi are essentially similar.

\section{Effect of pH on Qe of CCS}

$\mathrm{pH}$ level is one of the most important parameters for the adsorption of $\mathrm{Cu}$ (II) from an aqueous solution. To gain further insight into the adsorption process, the effect of $\mathrm{pH}$ on $\mathrm{Cu}$ (II) adsorption on CCS was studied in the $\mathrm{pH}$ range

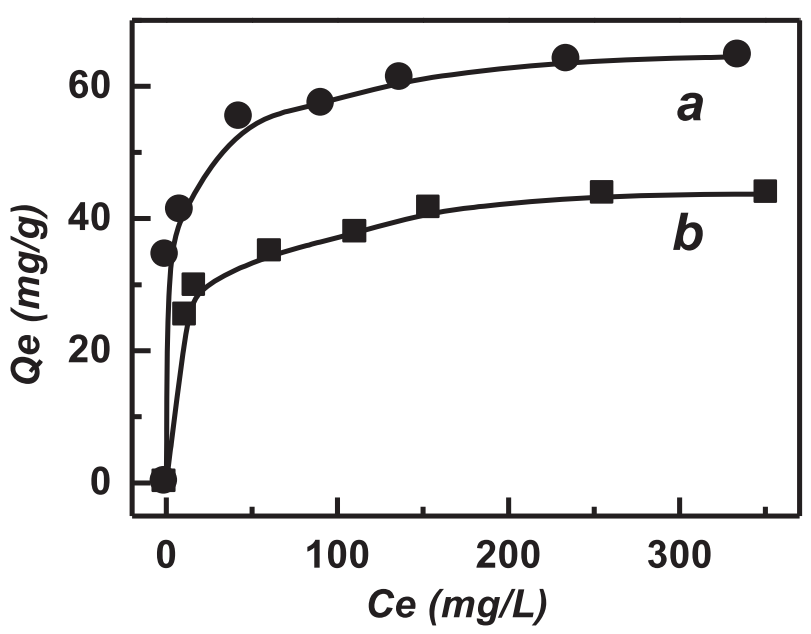

Fig. 2. Adsorption isotherm of Cu (II) onto CCS (a) and ECSi (b) in $\mathrm{CuSO}_{4}$ solution (pH5) at $30^{\circ} \mathrm{C}$.

Table 5. Parameters of Langmuir and Freundlich for adsorption of $\mathrm{Cu}$ (II) on CCS and ECSi.

\begin{tabular}{|c|c|c|c|c|c|c|}
\hline & \multicolumn{3}{|c|}{ Langmuir } & \multicolumn{3}{c|}{ Freundlich } \\
\hline & $\mathrm{K}_{\mathrm{L}}(\mathrm{L} / \mathrm{mg})$ & $\mathrm{Q}_{\max }$ & $\mathrm{R}^{2}$ & $\mathrm{~K}_{\mathrm{f}}$ & $\mathrm{n}$ & $\mathrm{R}^{2}$ \\
\hline ECSi & 0.071 & 45 & 1.00 & 17.9 & 6.3 & 0.97 \\
\hline CCS & 0.15 & 65 & 1.00 & 36 & 9.70 & 0.96 \\
\hline
\end{tabular}


Table 6. Effect of pH on adsorption amount of Cu (II) onto CCS.

\begin{tabular}{|c|c|c|c|c|c|}
\hline $\mathrm{pH}$ & 1 & 2 & 3 & 4 & 5 \\
\hline Qe (mg/g) & 0 & 0.4 & 39 & 44 & 55 \\
\hline
\end{tabular}

1 to 5 . The results are shown in Table 6 . The amount of $\mathrm{Cu}$ (II) adsorbed on CCS decreases rapidly as $\mathrm{pH}$ decreases, and is negligible when $\mathrm{pH}$ is below 2. In this case, the degree of ionization of the carboxyls of CCS is so small that it loses the electrostatic binding abilities with $\mathrm{Cu}$ (II), implying that the mechanism of the adsorption of $\mathrm{Cu}$ (II) to the CCS is ion exchange.

From the above experimental and analytical results, it can be noted that the adsorption capacity of CCS for $\mathrm{Cu}$ (II) $(65 \mathrm{mg} / \mathrm{g})$ is significantly higher than that of other sewage sludge-derived absorbents, such as sewage sludge carbon $(6.7 \mathrm{mg} / \mathrm{g})$ and sewage sludge carbon chemical activation with $\mathrm{ZnCl} 2$ (20.6 mg/g) [24]. The adsorption capacity of CCS is similar to that of commercial cation exchange resins [25, 26], indicating that CCS is a promising absorbent for removal of heavy metals from wastewater.

\section{FTIR}

FTIR spectra of dried sewage sludge (a), ECSi (b), and CCS (c) are shown in Fig. 3. In curve a in Fig. 3, the bands at $3,408 \mathrm{~cm}^{-1}$ and $1,654 \mathrm{~cm}^{-1}$ are attributed to the stretching vibration of $-\mathrm{OH}$ and $-\mathrm{C}=\mathrm{O}$ of sewage sludge, respectively. The adsorption band at 2,925 $\mathrm{cm}^{-1}$ could be the asymmetric vibration of $-\mathrm{NH}$. The $1,431 \mathrm{~cm}^{-1}$ is of phenolic -OH and -C-O stretching of carboxylates. The $1,032 \mathrm{~cm}^{-1}$ band could be the vibration of $-\mathrm{P}-\mathrm{O}-\mathrm{C}$ and $\mathrm{P}$ -OH of the phosphonate groups [27]. Comparing curve $b$ with curve a in Fig. 3, there is no appreciable difference between the two, suggesting that new infrared active groups have not been formed in ECSi. However, the band at $1,654 \mathrm{~cm}^{-1}$ in curve c broadens, evidently indicating that the density of carboxyl in CCS increases to some extent. This result agrees with its adsorption properties.

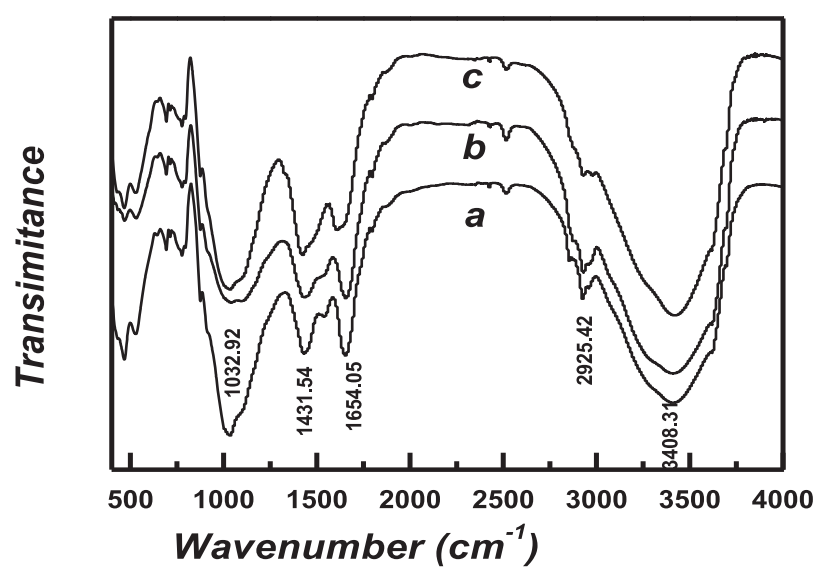

Fig. 3. FTIR spectra of dried sewage sludge (a), ECSi (b), and $\operatorname{CCS}(\mathrm{c})$.

\section{Conclusions}

Firstly, the synthesized conditions of ECS with good adsorption ability and mechanical strength were studied. The experimental results showed that the optimum conditions were as follows: the amount of the added epichlorohydrin and $\mathrm{NaOH}$ to $50 \mathrm{ml}$ of the mixture of dried sewage sludge and ethanol was $25 \mathrm{ml}$ and $5 \mathrm{~g}$, respectively. The reaction temperature was $60^{\circ} \mathrm{C}$ and the reaction time was $8 \mathrm{~h}$. And then carboxymethylation of ECS was achieved using chloroacetic acid as the etherification. The maximal adsorption capacity of CCS for $\mathrm{Cu}$ (II) is $65 \mathrm{mg} / \mathrm{g}$. IR spectrum analysis indicated that the density of carboxyl in CCS increases to some extent compared to ECS.

The experiment results showed that the adsorption properties of CCS for Cu (II) could be best described by the pseudo second-order model and Langmuir model, indicating that chemical adsorption is the rate-controlling step and the adsorption surface is closely homogenous. The mechanism that governs $\mathrm{Cu}$ (II) removal by CCS is an ion exchange. Therefore, the use of CCS for the removal of heavy metals from contaminated waters may be a novel and cost-effective alternative.

\section{Acknowledgements}

This work was supported by the Special Fund for Environmental Protection of Shandong Province under Grant No. SDHBYF-2012-06, and the SciTech Development Project of Shandong Province (No. 2014GGH202001); special thanks to Dr. Edward C. Mignot, Shandong University, for linguistic advice.

\section{References}

1. JIN L., ZHANG G.M., TIAN H.F. Current state of sewage treatment in China. Water Res. 66, 85, 2014.

2. KRÜGERO., GRABNER A., ADAM C. Complete survey of German Sewage Sludge ash. Environ. Sci. Technol. 48, 11811, 2014.

3. LIU T., LIU B., ZHANG W. Nutrients and heavy metals in biochar produced by sewage sludge pyrolysis: Its application in soil amendmen. Pol. J. Environ. Stud. 23, 271, 2014.

4. TANG B., ZHANG Z. Essence of disposing the excess sludge and optimizing the operation of wastewater treatment: Rheological behavior and microbial ecosystem. Chemosphere 105, 1, 2014.

5. SU W., TANG B., FU F. L., HUANG S.S., ZHAO S.Y., BIN L.Y., DING J.W., CHEN C.Q. A new insight into resource recovery of excess sewage sludge: Feasibility of extracting mixed amino acids as an environment-friendly corrosion inhibitor for industrial pickling. J. Hazard Mater. 279, 38, 2014.

6. BOUALEM T., DEBAB A., MARTÍMEZ DE YUSO A., IZQUIERDO M.T. Activated carbons obtained from sewage sludge by chemical activation: Gas-phase environmental applications. J. Environ. Manage. 140, 145, 2014.

7. MONSALVO V.M., MOHEDANO A.F., RODRIGUEZ J.J. 
Activated carbons from sewage sludge Application to aqueous-phase adsorption of 4-chlorophenol. Desalination 277, 377, 2011.

8. WANG X.J., XU X.M., LIANG X., WANG Y., LIU M., WANG X., XIA S.Q., ZHAO J.F., YIN D.Q., ZHANG Y.L. Adsorption of copper (II) onto sewage sludge-derived materials via microwave irradiation. J. Hazard Mater. 192, 1226, 2011.

9. HU J.L., HE X.W., WANG C.R., LI J.W., ZHANG C.H. Cadmium adsorption characteristic of alkali modified sewage sludge. Bioresour. Technol. 121, 25, 2012.

10. CHEN T., ZHANG Y.X., WANG H.T., LU W.J., ZHOU Z.Y., ZHANG Y.C., REN L.L. Influence of pyrolysis temperature on characteristics and heavy metal adsorptive performance of biochar derived from municipal sewage sludge. Bioresour. Technol. 164, 47, 2014.

11. VELGHE I., CARLEER R., YPERMAN J., SCHREURS S., D'HAEN J. Characterisation of adsorbents prepared by pyrolysis of sludge and sludge/disposal filter cake mix. Water Res. 46, 2783, 2012.

12. AGRAFIOTI E., KALDERIS D., DIAMADOPOULOS E. Arsenic and chromium removal from water using biochars derived from rice husk, organic solid wastes and sewage sludge. J. Environ. Manage. 133, 309, 2014.

13. RIVERA-UTRILLA J., GÓMEZ-PACHECO C.V., SÁNCHEZ-POLO M., LÓPEZ-PEÑALVER J.J., OCAMPOPÉREZ R. Tetracycline removal from water by adsorption/ bioadsorption on activated carbons and sludge-derived adsorbents. J. Environ. Manage. 131, 16, 2013.

14. KONG L.J., XIONG Y., TIAN S.H., LUO R.S., HE C., HUANG H.B. Preparation and characterization of a hierarchical porous char from sewage sludge with superior adsorption capacity for toluene by a new two-step pore-fabricating process. Bioresour. Technol. 146, 457, 2013.

15. WENG H.X., MA X.W., FU F.X., ZHANG J.J., LIU Z., TIAN L.X., LIU C.X. Transformation of heavy metal speciation during sludge drying: Mechanistic insights. J. Hazard Mater. 265, 96, 2014.

16. SIRIANUNTAPIBOON S., UNGKAPRASATCHA O. Removal of $\mathrm{Pb}^{2+}$ and $\mathrm{Ni}^{2+}$ by bio-sludge in sequencing batch reactor (SBR) and granular activated carbon-SBR (GAC-SBR) systems. Bioresour. Technol. 98, 2749, 2007.

17. KIM B.S., LIM S.T. Removal of heavy metal ions from wa- ter by cross-linked carboxymethyl corn starch. Carbohyd. Polym. 39, 217, 1999.

18. ROHDE R.K. Spectrophotometric determination of copper in Lead, Tin, Aluminum, Zinc, and their alloys with Biscyclohexanone Oxalyldihydrazone. Anal. Chem. 38, 911, 1966.

19. GÓMEZ-CARRACEDO A., SOUTO C., MARTÍNEZPACHECO R., CONCHEIRO A., GÓMEZ-AMOZA J.L. Incidence of drying on microstructure and drug release profiles from tablets of MCC - lactose - Carbopol $^{\circledR}$ and MCC - dicalcium phosphate - Carbopol $^{\circledR}$ pellets. Eur. J. Pharm. Biopharm. 69, 675, 2008.

20. CHOI S.B., YUN Y.S. Biosorption of cadmium by various types of dried sludge: An equilibrium study and investigation of mechanisms. J. Hazard Mater. 138, 378, 2006.

21. JIN X.Y., YU B., CHEN Z.L., ARACENA J.M., THRING R.W. Adsorption of Orange II dye in aqueous solution onto surfactant-coated zeolite: Characterization, kinetic and thermodynamic studies. J. Colloid Interf. Sci. 435, 15, 2014.

22. NADAVALA S.K., SWAYAMPAKULA K., BODDU V.M., ABBURI K. Biosorption of phenol and o-chlorophenol from aqueous solutions on to chitosan-Calcium alginate blended beads. J. Hazard Mater. 162, 482, 2009.

23. SABER-SAMANDARI S., SABER-SAMANDARI S., NEZAFATI N., YAHYA K. Efficient removal of lead (II) ions and methylene blue from aqueous solution using chitosan/ Fe-hydroxyapatite nanocomposite beads. J. Environ. Manage. 146, 481, 2014.

24. ROZADA F., OTERO M., MORÁN A., GARCÍA A.I. Adsorption of heavy metals onto sewage sludge-derived materials. Bioresour. Technol. 99, 6332, 2008.

25. CARREON-ALVAREZ A., HERRERA-GONZALEZ A., CASILLAS N., PRADO-RAMIREZ R., ESTARRON-ESPINOSA M., SOTO V., CRUZ W. D. L., BARCENA-SOTO M., GOMEZ-SALAZAR S. Cu (II) removal from tequila using an ion-exchange resin. Food Chem. 127, 1503, 2011.

26. ABO-FARHA S.A., ABDEL-AAL A.Y., ASHOUR I.A., GARAMON S.E. Removal of some heavy metal cations by synthetic resin purolite C100. J. Hazard Mater. 169, 190, 2009.

27. WON S.W., CHOI S.B., YUN Y.S. Binding sites and mechanisms of cadmium to the dried sewage sludge biomass. Chemosphere 93, 146, 2013. 
